\title{
Utilizando a equoterapia como ferramenta psicopedagógica para crianças com necessidades educativas especiais
}

\section{Using equine-therapy as a psychopedagogical tool for children with special educational needs}

Utilizando la equinoterapia como herramienta psicopedagógica para niños con necesidades educativas especiales

\author{
Lisiane Pereira de Jesus ${ }^{1}$ \\ Heloisa Bruna Grubits Freire ${ }^{2}$ \\ Janaína Lúcia Rodrigues Bento ${ }^{3}$ \\ Delarim Martins Gomes ${ }^{4}$
}

${ }^{1}$ Médica Veterinária, Professora da Universidade Federal de Mato Grosso (UFMT), Doutora em Zootecnia, Mestre em Ciências Veterinárias, Especialista em Equoterapia pela Universidade de Brasília, Coordenadora do Centro de Equoterapia da UFMT (CEEq).E-mail: equoterapia@ufmt.br

${ }^{2}$ Psicóloga, Professora na Universidade Católica Dom Bosco (UCDB), Doutora em Ciências Biomédicas pela Universidade Estadual de Campinas (UNICAMP), Mestre em Psicologia da Saúde pela UCDB, Especialista em Sociopsicomotricidade Ramain-Thiers, Instrutora de Equitação. E-mail: grubitshb@hotmail.com

${ }^{3}$ Psicóloga, Professora na Universidade de Cuiabá (UNIC), Doutoranda do Programa de Pós-graduação em Educação pela UFMT, Mestre em Educação, Especialista em Relações Raciais em Educação, Especialista em Psicologia Social. E-mail: janainapsicologia@hotmail.com

${ }^{4}$ Pedagogo, Professor de Organização e Funcionamento da Educação Básica (UFMT) , Doutor em Educação, Mestre em Filosofia.

E-mail: delarim@hotmail.com 
Resumo: a Equoterapia favorece o desenvolvimento da capacidade de manter a atenção e concentração, estabelecer vínculos afetivos e a autoconfiança dos indivíduos que a praticam, assumindo caráter de suma importância, se aliada ao processo pedagógico de crianças com distúrbios de aprendizagem diversos. Essa prática representa uma nova possibilidade terapêutica, que influencia positivamente no processo ensino-aprendizagem, promovendo a inserção de crianças que apresentam alguma dificuldade, seja ela falta de atenção, memória, raciocínio, dislexia, disgrafia, dentre outras. Este estudo objetivou utilizar a Equoterapia como ferramenta psicopedagógica para crianças com Transtorno do Espectro Autista, melhorando o desempenho escolar e contribuindo com o aprendizado e convívio social do praticante. A Equoterapia auxilia na melhora das relações sociais das crianças autistas na escola, observado na relação tanto com colegas quanto professores, o que indiretamente contribui para melhor rendimento escolar do praticante. Também foram observados benefícios com relação à motricidade, comunicação verbal e interação social.

Palavras- chave: equoterapia; autismo; necessidades educativas especiais.

\begin{abstract}
: equine-therapy favors the development of the capacity to maintain attention and concentration, to establish affective bonds and the self-confidence of the individuals who practice it, assuming a character of paramount importance, allied with the pedagogical process of children with diverse learning disorders. This practice represents a new therapeutic possibility, which positively influences the learning teaching process, promoting the insertion of children who present some difficulty, be it lack of attention, memory, reasoning, dyslexia, dysgraphia, among others. This study aimed to use Equinetherapy as a psychopedagogical tool for children with Autism Spectrum Disorder, improving school performance and contributing to the practitioner's learning and social life. Equine therapy helps improve the social relations of autistic children in school, observed in the relationship with both colleagues and teachers, which indirectly contributes to a better school performance of the practitioner. Benefits were also observed regarding motor skills and verbal communication.
\end{abstract}

Keywords: equine-therapy, autism, special educacional needs.

Resumen: la Equinoterapia favorece el desarrollo de la capacidad de mantener la atención y concentración, establecer vínculos afectivos y la autoconfianza de los individuos que la practican, asumiendo carácter de suma importancia, aliada al proceso pedagógico de niños con trastornos de aprendizaje diversos. Esta práctica representa una nueva posibilidad terapéutica, que influye positivamente en el proceso de enseñanza aprendizaje, promoviendo la inserción de niños que presentan alguna dificultad, ya sea falta de atención, memoria, raciocinio, dislexia, disgrafía, entre otras. Este estudio objetivó utilizar la Equoterapia como herramienta psicopedagógica para niños con Trastorno del Espectro Autista, mejorando el desempeño escolar y contribuyendo con el aprendizaje y convivencia social del practicante. La Equinoterapia auxilia en la mejora de las relaciones sociales de los niños autistas en la escuela, observado en la relación tanto con colegas y profesores, lo que indirectamente contribuye para mejor rendimiento escolar del practicante. Los beneficios también fueron relacionados con las habilidades de motor y verbal

Palabras clave: equinoterapia, autismo, necesidades educativas especiales. 
Utilizando a equoterapia como ferramenta psicopedagógica para crianças com necessidades educativas especiais

\section{INTRODUÇÃO}

Considera-se um aluno com Necessidades Educativas Especiais (NEE) quando, ao longo da sua escolarização, ele apresenta algum problema de aprendizagem que necessite de mais recursos educacionais e de atenção específica.

O objetivo da educação para os alunos com NEE é que estes superem as suas dificuldades, partindo do pressuposto de que cada criança tem o seu ritmo próprio de aprendizagem e que aprende de acordo com as suas capacidades.

Para alcançar esse objetivo, é importante que se elaborem programas educativos que se façam adequados às caraterísticas individuais de cada criança.

A terapia com equídeos está sendo amplamente utilizada em muitos países do mundo. Nos últimos anos, tem se destacado como recurso terapêutico comumente aplicado nas áreas da saúde e educação. Na área da saúde, é uma atividade que exige a participação do corpo inteiro, contribuindo para o desenvolvimento do tônus e da força muscular, relaxamento, conscientização do próprio corpo, equilíbrio, aperfeiçoamento da coordenação motora, atenção, autoconfiança e autoestima. Na área educacional, através da relação com cavalo, o indivíduo, em tratamento, encontra subsídio para a reeducação, reabilitação e educação, além de ser favorecida uma interação afetiva.

Essa prática requer do praticante a atenção concentrada durante o tempo em que a sessão se desenvolve. Este é um fator bastante importante para o bom desempenho do aluno na escola, pois a atenção é a base do aprendizado

Uma vez que favorece o desenvolvimento da capacidade de manter a atenção e concentração, de estabelecer vínculos afetivos e autoconfiança dos indivíduos que a praticam, a equoterapia assume um caráter de suma importância, se aliada ao processo pedagógico de crianças e adolescentes com necessidades educativas especiais (NEE).

Cavalgar auxilia as crianças com disfunções da memória, porque exige planejar e criar estratégias, que são progressivamente memorizadas. Isto não é fácil de ser executado, e é necessário prender pela repetição, memorizar e, pela cuidadosa explanação, completar tarefas cotidianas. 
É notória as dificuldades que as crianças com autismo têm em muitos ambientes educacionais. Para minimizar esse problema, tem-se desenvolvido programas alternativos e estratégias de intervenção que em sua maioria enfatizam a correção das dificuldades comportamentais, como por exemplo a socialização, para melhorar o rendimento educacional. No entanto outro aspecto do problema deve ser considerado: as necessidades específicas de aprendizagem dessa população especial. As necessidades envolvidas incluem dificuldades organizacionais, distração, problemas em sequenciar, falta de habilidade em generalizar, entre outros.

Nesse sentido, muitos autores se dedicaram a avaliar os benefícios da Equoterapia em crianças com transtorno do espectro autista (BASS; DUCHOWNY; LLABRE, 2009 ; WARD et al., 2013; HOLM et al., 2014; GABRIELS et al., 2015; PETTY et al., 2017).

Objetivou-se utilizar a Equoterapia como ferramenta psicopedagógica para crianças com necessidades educativas especiais, dificuldade de aprendizagem, falta de atenção, memória ou raciocínio, voltando-se para portadores de Transtorno do Espectro Autista (TEA) e melhorando o desempenho escolar e contribuindo com o aprendizado e convívio social desses praticantes.

\section{MATERIAIS E MÉTODOS}

Este projeto foi aprovado mediante Edital Universal FAPEMAT 005/2015 e faz parte do Programa de Extensão Centro de Equoterapia da UFMT, aprovado pelo Edital PROEXT 2016. Foi desenvolvido em três módulos de atendimento, com duração de 6 a 8 meses cada um, dependendo da especificidade do público-alvo. Os resultados aqui descritos referem-se ao público-alvo atendido no primeiro módulo.

O público-alvo foi selecionado mediante entrevista com professores, pais e responsáveis. Foram selecionadas crianças com transtorno do espectro autista, de ambos os sexos, provenientes de escolas públicas e que apresentavam dificuldades no processo de ensino-aprendizagem. A participação da criança foi condicionada ao consentimento dos pais ou responsáveis legais, sendo obrigatório o preenchimento do Termo de Consentimento Livre e Esclarecido (TCLE) e Termo de Assentimento do Menor. O Projeto foi aprovado pelo Comitê de Ética em Pesquisa da UFMT (CEP/Humanidades/ 
Utilizando a equoterapia como ferramenta psicopedagógica para crianças com necessidades educativas especiais

UFMT), sob comprovante na Plataforma Brasil n. 123864/2015, CAAE 51577515.9.0000.5690.

Foram critérios para inclusão para este estudo: crianças em idade escolar, com histórico de dificuldades de aprendizagem e apresentação de laudo médico ou psicológico atestando o transtorno do espectro autista. Foram critérios excludentes: crianças não alfabetizadas, presença de comorbidades e condição socioeconômica, considerando o aspecto extensionista da ação destinada exclusivamente a crianças em situação de vulnerabilidade econômica.

A pesquisa foi desenvolvida nas dependências de um dos parceiros do programa, o Rancho Dourado, que consta de espaço físico adequado à prática de Equoterapia, uma vez que disponibiliza normalmente esse tipo de serviço, entre outras atividades, como escolinha de equitação, hipismo rural e clássico etc.

As sessões de Equoterapia tiveram início no dia 02/05/2016 e foram conduzidas pelos bolsistas e estagiários participantes do Programa, sendo estes acadêmicos dos cursos de pedagogia, psicologia e zootecnia da Universidade Federal de Mato Grosso (UFMT) e de fisioterapia da Universidade de Cuiabá (UNIC) e supervisionados por profissional da área de fisioterapia da equipe multiprofissional de equoterapia do Rancho Dourado e por docentes da UFMT das áreas de Medicina Veterinária e Zootecnia e da UNIC das áreas de Psicologia e Educação.

As sessões ocorreram em intervalos semanais, uma vez por semana, durante oito meses. A duração de cada sessão foi de 30 minutos de atividades sobre o cavalo e 20 minutos de atividades lúdico-pedagógicas posteriores à montaria. As sessões foram finalizadas em dezembro de 2016.

As sessões de Equoterapia não foram restritas apenas à montaria, mas envolveram uma série de atividades que complementam a prática no cavalo. Essas atividades incluíram a realização de jogos voltados ao desenvolvimento das habilidades cognitivas (concentração, memória, atenção) e sociais, adaptadas à Equoterapia, atividades propostas no Curso de Vivência em Equoterapia (2012) ministrado por profissionais da Associação Nacional de Equoterapia (ANDE - BRASIL), bem como outras atividades desenvolvidas por profissionais da psicologia e pedagogia com objetivo de estimular 
a concentração e memória dos praticantes através do uso do cavalo, bem como de associar atividades educativas que estimulassem o desenvolvimento psicopedagógico. O plano orçamentário do projeto previa a aquisição de material pedagógico, jogos, livros e outros artefatos que deram suporte às atividades lúdicas complementares à Equoterapia.

O registro das informações de cada praticante foi realizado após cada sessão, pelos bolsistas, estagiários e mediadores que acompanharam o praticante durante a sessão de equoterapia, sendo realizado o preenchimento de uma "ficha de acompanhamento das sessões", abordando aspectos motores, psicossociais e cognitivos que serviam como base para acompanhar o progresso de cada praticante ao final do projeto. Foram realizados, também, diversos registros fotográficos durante os atendimentos. A coleta de dados incluiu: a) anamnese e entrevista com pais ou responsáveis realizada em momentos pontuais no decorrer da pesquisa; b) entrevista com professores para acompanhar o desempenho dos praticantes no ambiente escolar; c) preenchimento da Ficha de Acompanhamento das Sessões; d) Registro fotográfico; e) Aplicação de Teste para avaliar habilidades de leitura no início e ao final do estudo.

O teste selecionado para utilizar na avaliação do público-alvo foi selecionado pelo pedagogo de forma a contemplar, da melhor forma, o perfil dos praticantes que fariam parte do projeto. Realizaram-se três oficinas para desenvolver o protocolo e para capacitação dos bolsistas e estagiários para aplicação do teste Provas de Avaliação dos Processos de Leitura (PROLEC) mais utilizado, nas investigações científicas, sobre dificuldades de aprendizagem; tem o objetivo de oferecer uma ferramenta capaz de identificar as dificuldades que interferem no processo de desenvolvimento da leitura, atuando como um guia para orientar programas de recuperação.

Após a capacitação de toda equipe envolvida no projeto de equoterapia, foi enviado um comunicado aos pais e responsáveis dos praticantes selecionados para participarem do projeto, para que comparecessem com a criança em dia e horário determinado para aplicação do PROLEC pelas bolsistas dos cursos de psicologia e pedagogia. Um mês antes do início das sessões de equoterapia, os praticantes foram submetidos ao teste PROLEC e, em uma segunda vez, ao final do estudo. 
Utilizando a equoterapia como ferramenta psicopedagógica para crianças com necessidades educativas especiais

O teste é composto por 10 provas que investigam o nível de leitura do avaliando e o classifica como: (N) normal, (D) dificuldade e (DD) dificuldade grande.

A primeira prova é utilizada para averiguar se o avaliando conhece as letras do alfabeto; A segunda, para identificar se o escolar consegue perceber erros na grafia das palavras; A terceira para saber se o avaliando consegue diferenciar palavras reais de pseudopalavras; A prova seguinte avalia a habilidade de ler palavras reais e é seguida pela prova que avalia a habilidade de ler palavras inventadas; Depois, o teste apresenta duas provas que medem as habilidades de lidar com a gramática e com sinais de pontuação e é finalizado com provas que identificam se o avaliando é capaz de compreender o que está escrito.

Dessa forma, a busca desta pesquisa foi abrir e mergulhar na tentativa, descrever, compreender e interpretar as relações, que pudermos captar, tanto entre nós e a criança da equoterapia, como a criança e o cavalo, no intuito de compreender o quanto a equoterapia pode favorecer e/ou contribuir no processo de desenvolvimento e, consequentemente, no ensino-aprendizagem dos sujeitos pesquisados. Descartou-se, dessa maneira, a ideologia da neutralidade na pesquisa uma vez que o movimento necessário é permitir se tocar e ser tocado, deixando ser observado e observar, em um movimento de mergulho na busca pela compreensão da percepção do outro.

A pesquisa qualitativa é multimetodológica quanto ao seu foco, envolvendo abordagens interpretativas e naturalísticas dos assuntos. Isto significa que o pesquisador qualitativo estuda coisas em seu ambiente natural, tentando dar sentido ou interpretar os fenômenos, segundo o significado que as pessoas the atribuem (DENZIN; LINCOLN, 1994, p.2).

Segundo Minayo (2002, p. 17), a pesquisa qualitativa possibilita melhor descrever as observações colhidas, uma vez que a percepção é subjetiva, e não existe objeto sem sujeito e sujeito sem objeto, sendo preciso penetrar no universo conceitual dos sujeitos, para compreender como e qual sentido eles dão aos acontecimentos e às interações sociais da vida diária. É o sentido dado às experiências que constitui a realidade, socialmente construída.

A pesquisa foi embasada na abordagem qualitativa, por ter a pretensão de compreender com ênfase intersubjetiva o sistema de significados. 
Segundo Minayo (2002), a pesquisa qualitativa possibilita a emissão de respostas a questões muito peculiares ao estudo que realizamos, uma vez que esta considera o universo de significados, motivações, aspirações, crenças, valores e atitudes, o que corresponde a um espaço mais profundo das relações, dos processos e dos fenômenos que nesta pesquisa investigamos.

A abordagem qualitativa leva em consideração que as ações das pessoas decorrem em função de seus valores, sentimentos, crenças e percepções. Suas ações têm sempre um sentido, um significado que não se dá a conhecer em um primeiro instante, podendo aproximar do desvelado através dessa metodologia. É o participante que dá sentido à trama de significações que envolvem os objetos percebidos no mundo vivido no qual está inserido.

Na observação participante, segundo Minayo (2002), o pesquisador vivencia pessoalmente o evento de sua análise para melhor compreendê-lo, percebendo e agindo de acordo com as suas interpretações do contexto e das relações sociais, procura entender as ações no contexto da situação observada.

As observações em equipe e observações na vida real consistem em: observar o praticante por vários ângulos, facilitando assim confrontar os dados colhidos para verificar posteriormente as predisposições, que são normalmente feitas no ambiente real, registrando-se os dados à medida que ocorre o evento, reduzindo tendências seletivas e a deturpação na reevocação (LAKATOS; MARCONI, 2001).

A partir das observações participantes, foram feitos os registros de informações, através de fotos, bem como por meio de ficha de acompanhamento e registros das atividades desenvolvidas por meio de relatórios mensais de cada praticante de equoterapia. Esses instrumentos de coleta de informações possibilitaram uma análise compreensiva do projeto de pesquisa desenvolvidos, apontado para os seguintes resultados de pesquisa.

\section{RESULTADOS E DISCUSSÃO}

Neste projeto de pesquisa, bem mais que registrar os fatos, objetivamos analisar compreensivamente, bem como interpretar em busca dos significados contidos nos atos, ritos, performances dos nossos sujeitos de pesquisa, e não apenas descrevê-los. 
Utilizando a equoterapia como ferramenta psicopedagógica para crianças com necessidades educativas especiais

Sendo assim, conseguimos interpretar, por meio de nossas análises compreensivas, que a equoterapia é um importante recurso psicopedagógico para crianças com diagnóstico de TEA que apresenta necessidades educativas especiais, com dificuldade de aprendizagem. A equoterapia, além de possibilitar aos sujeitos pesquisados melhora no desempenho escolar e contribuir com o ensino-aprendizado por favorecer a concentração e convívio social do praticante, também possibilitou uma maior interação do praticante com o cavalo e com a natureza, o que favoreceu o desenvolvimento de vínculos afetivos, bem como a melhora na comunicação e no convívio social.

Outro aspecto observado durante os atendimentos foi a melhora na autoestima e autoconfiança do praticante, melhora do equilíbrio, coordenação motora, consciência corporal, atenção e memória.

A aplicação do PROLEC demostrou que, durante o estabelecimento de rapport, nenhum praticante demonstrou resistência, mostrando-se bastante abertos respondendo às perguntas as quais eram solicitadas sobre família, mãe e sobre si mesmos.

Como o teste não é específico para portadores do TEA e, portanto, não considera as especificidades desse público em particular, observou-se dificuldade de todos praticantes em passar da 2a etapa; a pontuação hora apresentada na Tabela 1 considera apenas a pontuação da 1ạ etapa (inicial), pois foi a única realizada por quase todos praticantes, com apenas uma exceção. O objetivo do Teste foi avaliar o grau de dificuldade de cada praticante para desenvolver protocolos específicos para cada indivíduo durante as sessões de Equoterapia.

No teste, seis praticantes conseguiram responder prontamente à primeira fase, reconhecendo as letras do alfabeto, sem queixas. Quando chegou a segunda fase, no reconhecimento das palavras iguais e diferentes, houve uma maior dificuldade e, nesse momento, cerca de $40 \%$ dos praticantes apresentaram alguma dificuldade. Em média, os praticantes obtiveram dezesseis pontos na primeira fase da prova, classificando-se como tendo dificuldade grande (DD), segundo o manual do teste PROLEC. Apenas um praticante concluiu as dez etapas do teste.

Durante o feedback com a família, uma das mães despertou a nossa atenção para algo importante. Segundo essa mãe, seu filho participante 
sabe formar palavras, a sua dificuldade em relação ao teste foi que a letra era de forma e em itálico, de difícil reconhecimento, mas, quando escreveu a mesma palavra em uma folha, ele soube ler perfeitamente. Realmente essa é uma característica do autista, ser mais visual e lembrar da forma que foi aprendido, se a criança está sendo alfabetizada em letra de forma provavelmente só identificará as letras de forma.

Os relatórios das professoras das escolas onde estudam os alunos praticantes de equoterapia, relatam em sua maioria um excelente progresso no decorrer do ano letivo, ótimo desempenho em todas as atividades propostas no ano em questão, melhora na escrita obtendo excelentes progressos atingindo um nível de escrita alfabética, produzindo frases e pequenos textos. Também, bom desempenho na leitura interpretativa, demonstrando um ótimo raciocínio lógico, opera adições simples e subtração.

Entre os diversos aspectos apontados pelas professoras, o mais enfatizado foi a melhora no processo de socialização com a turma, sendo descrito muitas vezes como algo surpreendente. Há relatos de professoras de aluno que muitas vezes demonstrava desinteresse nas brincadeiras, mantendo-se afastado, mudou o comportamento a tal ponto de manifestar algumas vezes ordem de comando em determinadas brincadeiras.

$\mathrm{Na}$ Tabela a seguir, serão descritos os resultados individuais para cada praticante avaliado: 
Utilizando a equoterapia como ferramenta psicopedagógica para crianças com necessidades educativas especiais

Tabela 1 - Identificação da Amostra, Caracterização do Praticante e Pontuação na 1 à etapa do PROLEC

\begin{tabular}{|c|c|c|}
\hline Identificação & Caracterização do Praticante & $\begin{array}{c}\text { Pontuação PROLEC } \\
\text { (1 a aplicação) }\end{array}$ \\
\hline Praticante 1 & $\begin{array}{l}\text { C.V.S.X., sexo feminino, } 10 \text { anos, } 4 \text { o ano do En- } \\
\text { sino Fundamental }\end{array}$ & 17 pontos (DD) \\
\hline Praticante 2 & D.O.J, sexo masculino, 7 anos, $1 \stackrel{0}{ }$ ano do EF & 16 pontos (DD) \\
\hline Praticante 3 & $\begin{array}{l}\text { R.S.D, sexo masculino, } 11 \text { anos, cursando o } 5^{\circ} \\
\text { ano do ensino fundamental }\end{array}$ & 20 pontos $(N)$ \\
\hline Praticante 4 & $\begin{array}{l}\text { A.H. M. S. L., } 6 \text { anos, sexo masculino, 10 ano } \\
\text { do EF }\end{array}$ & 9 pontos (DD) \\
\hline Praticante 5 & $\begin{array}{l}\text { A. L. M. S. L., de } 7 \text { anos, sexo masculino, } 2 \text { 을 } \\
\text { ano do EF }\end{array}$ & 12 pontos (DD) \\
\hline Praticante 6 & $\begin{array}{l}\text { E. W. P. R., } 7 \text { anos, sexo masculino, 2ㅇ ano do } \\
\text { EF }\end{array}$ & $\begin{array}{c}\text { Negou-se a realizar } \\
\text { o teste }\end{array}$ \\
\hline Praticante 7 & $\begin{array}{l}\text { G.M.B.D.S, } 6 \text { anos, do sexo masculino, 10 ano } \\
\text { do EF }\end{array}$ & 7 pontos (DD) \\
\hline
\end{tabular}

Considerando que o transtorno do espectro autista apresenta particularidades inerentes a cada indivíduo, torna-se difícil compilar os resultados de todos praticantes como um resultado único e generalista, quando o que ocorre na realidade são respostas individualizadas considerando características específicas de cada indivíduo avaliado, portanto descreveremos aspectos biopsicomotores, divididos em três grupos, para facilitar o entendimento: aspectos motores, psicossociais e cognitivos e de aprendizado. Os aspectos motores referem-se a orientação, lateralidade, coordenação motora, equilíbrio e postura sobre o cavalo; os aspectos psicossociais envolvem autonomia, autoestima, autoconfiança, socialização e interação; e os aspectos cognitivos avaliados compreendem atenção e concentração durante as atividades, refletindo no desempenho do praticante no ambiente escolar. Todos os aspectos elencados foram observados e registrados, no decorrer do projeto, individualmente para cada praticante, tendo como base as fichas de acompanhamento das sessões, os relatórios de campo e as entrevistas com pais e professores. 


\section{Aspectos motores}

Os praticantes de forma geral demonstraram possuir orientação, lateralidade, coordenação motora, equilíbrio e uma postura adequada em cima do cavalo, o que facilitou muito a realização de todos os exercícios propostos pela equipe durante o projeto. Embora alguns tenham apresentado dificuldades iniciais principalmente relacionadas a orientação e lateralidade, os praticantes, durante o período de desenvolvimento do estudo, demonstraram um grande avanço nesses aspectos motores.

Ferreira e Thompson (2002) afirmam que o autista apresenta dificuldade de compreender seu corpo em sua globalidade, em segmentos, assim como seu corpo em movimento. Quando partes do corpo não são percebidas e as funções de cada uma são ignoradas, pode-se observar movimentos, ações e gestos pouco adaptados. O distúrbio na estruturação do esquema corporal prejudica também o desenvolvimento do equilíbrio estático, da lateralidade, da noção de reversibilidade; estas, funções de base necessárias à aquisição da autonomia e aprendizagens cognitivas.

Através da equoterapia, percebemos uma melhora nos aspectos motores, corroborando também achados de outros autores que pesquisaram os efeitos da Equoterapia sobre o desempenho funcional e função motora dos indivíduos avaliados (MORAES et al., 2016; CHAMPAGNE; CORRIVEAU; DUGAS, 2017; STERGIOU et al. 2017).

\section{Aspectos psicossociais}

Com relação aos conceitos psicossociais como autoconfiança, socialização, interação e reagir bem a frustrações, o Praticante 1 (P1) apresentou oscilações durante o projeto, mas obteve melhora no contexto geral demonstrando que a Equoterapia contribuiu para que o praticante evoluísse nesses aspectos. Embora Jang et al. (2016) não tenham observado melhorias nos parâmetros psicossociais ou emocionais em crianças com paralisia cerebral, talvez em função da especificidade do seu público-alvo, outros autores mencionaram evolução em vários desses aspectos ao trabalhar com crianças com TEA (ANDERSON; MEINTS, 2016; CERINO et al., 2016; LLAMBIAS et al., 2016; HARRIS; WILLIAMS, 2017). 
Utilizando a equoterapia como ferramenta psicopedagógica para crianças com necessidades educativas especiais

Nos aspectos relacionados à socialização, interação, autoconfiança e autonomia, o Praticante 2 (P2) não apresentou dificuldade em nenhuma sessão, sendo sempre comunicativo e confiante. Segundo Bender e Guarany (2016), a equoterapia tem apresentado resultados positivos nesses aspectos, ou seja, melhoras no humor, contato visual, linguagem (conversa), cuidados com animais, melhoria nos comportamentos sociais e aumento de interesse por novas tarefas.

Apesar de ser uma criança bastante empática e sociável, o Praticante 3 (P3), em algumas sessões, apresentou episódios de irritabilidade, no entanto, ao longo dos meses, diminuiu significativamente tal comportamento, sendo eles substituídos por conversas acerca de suas frustrações, técnicas de relaxamento corporal e aproximação ao cavalo de sua preferência. Souza e Silva (2015), ressaltam que a atividade terapêutica da Equoterapia inicia-se no instante em que o indivíduo entra em contato com o animal; no primeiro momento, o cavalo passa a representar um problema, exigindo que o praticante aprenda a lidar, aprendendo também a maneira correta de montar ou descobrindo meios para fazer com que o animal aceite seus comandos, essa relação contribui para o desenvolvimento da sua autoconfiança, afetividade e autonomia, trabalhando também os limites.

Gabriels et al. (2015), avaliando crianças e adolescentes autistas, observaram melhorias significativas no grupo assistido pela equoterapia em comparação com o controle nos aspectos irritabilidade e hiperatividade a partir da quinta semana de intervenção.

O Praticante 4 (P4) continuou mantendo um alto nível de independência e apresentou uma redução na aparente frustração que surgia sempre que precisava de ajuda, aceitando-a com mais entusiasmo. A relação com o cavalo também melhorou, pois, nas primeiras sessões, ele apresentava uma grande apreensão em relação ao animal e, com poucas sessões, ele passou a se portar de maneira muito mais confiante. Cerino et al. (2016) propõem intervenções assistidas por animais como abordagens complementares capazes de facilitar a verbalização dos estados internos do paciente e promover o bem-estar psicológico através do desenvolvimento de um vínculo com o animal.

Inicialmente o Praticante 5 (P5) apresentou dificuldade em questões relacionadas a socialização, interação, reação às frustrações e estado emo- 
cional, as quais, com a realização das sessões de Equoterapia, mostraram oscilações, porém considerando-se nítido o desenvolvimento positivo obtido em prol da sua qualidade de vida. Os resultados de estudo desenvolvido por Cuypers, De Ridder e Strandheim (2011) indicam que a equitação terapêutica teve um efeito positivo em vários domínios do comportamento social e qualidade de vida nos indivíduos avaliados.

O Praticante 6 (P6) apresentou inicial dificuldade em questões de autonomia e reação às frustrações. No decorrer das sessões, apresentou melhora em sua socialização. O praticante não respondia muito às interações por parte das auxiliares, mantendo-se fechado e com atenção somente individual, interação essa que progrediu evidentemente em cada sessão, o praticante passou a interagir com a equipe, com a qual cada vez mais desenvolveu vínculo.

Notou-se também nítida melhora em suas reações à frustração, as quais, nas primeiras sessões, eram negativas, agressivas e denotavam perda de interesse nas atividades realizadas em grupo, passando para reações mais neutras e até mesmo reações que demonstravam alegria e conotando sentido de brincadeira, evidenciando sua compreensão acerca desta. Observou-se melhora em sua autonomia, uma vez que as ações do praticante eram inicialmente mais dependentes de solicitações e interações durante as sessões e, no decorrer das atividades, passou a se desenvolver e fluir, agindo mais conforme sua vontade e decisão própria, trazendo consigo ainda o crescimento de sua autoconfiança.

O'Haire (2013), revisando 14 estudos sobre os efeitos da Equoterapia para crianças com TEA, afirma que os resultados relatados incluíram melhorias em múltiplas áreas de funcionamento conhecidas como prejudicadas no TEA, notadamente aumento da interação social e da comunicação foram evidenciados na maioria dos estudos. Borioni et al. (2012) observaram melhora geral na autonomia e integração social dos indivíduos avaliados submetidos à intervenção com o uso do cavalo.

No decorrer das sessões de equoterapia, foi possível observar uma melhora significativa em relação ao comportamento interpessoal do Praticante 7 (P7), a partir da nona sessão,0 o praticante começou a interagir socialmente com a equipe de modo satisfatório, corroborando os achados 
de Lanning et al. (2014), que afirmam que se podem observar melhorias significativas no funcionamento físico, emocional e social da criança com TEA após as primeiras 6 semanas de tratamento.

O envolvimento em atividades é essencial para o desenvolvimento e, muitas vezes, é reduzido em crianças com transtorno do espectro autista que têm compromisso limitado em atividades ou relacionamentos; incluir cavalos em sessões de terapia ocupacional pode ser uma adição valiosa aos tratamentos convencionais para aumentar esses parâmetros (LLAMBIAS et al., 2016).

Os resultados de Anderson e Meints (2016) demonstraram que a equoterapia aumentou a empatia e reduziu comportamentos indesejáveis em crianças com TEA, no entanto os achados também indicaram que a socialização e a comunicação não foram afetados pela intervenção. A Equoterapia pode não alterar todo o comportamento da criança, mas pode melhorar os aspectos específicos do funcionamento social e também reduzir os traços de TEA indesejáveis, outro aspecto a ressaltar sobre este estudo é o tempo de duração, os praticantes foram acompanhados durante cinco semanas, tempo que pode não ser suficiente para os autores perceberem efeitos sobre a socialização e comunicação, que são observados em protocolos mais duradouros como no caso de nosso estudo, que foi executado em 32 semanas.

\section{Aspectos cognitivos e aprendizado}

Segundo relatos da mãe, o P1 está no quarto ano, mas agora que está sendo alfabetizado, aprendendo o alfabeto e algumas formações silábicas, com mais desprendimento, autonomia e interesse.

Segundo entrevista realizada com a professora, o P2, obteve um excelente progresso no decorrer do ano letivo. Teve ótimo desempenho em todas as atividades propostas no período, sempre responsável em realizar suas atividades. Na escrita, obteve um excelente progresso atingindo um nível de escrita alfabética, produzindo frases e pequenos textos. Apresentou leitura interpretativa, demonstrando um ótimo raciocínio lógico, opera adições simples e subtração. Quanto à sua socialização com a turma foi surpreendente, no início não demonstrava interesse nas brincadeiras, 
mantendo-se afastado. Porém, com o tempo, isso mudou a tal ponto que manifesta algumas vezes ordem de comando em determinadas brincadeiras, demonstrando autoconfiança e autonomia.

Considera-se que o tratamento com equoterapia e atividades pedagógicas realizados com o P3 atingiram resultados positivos e satisfatórios, promovendo ampliação de habilidades sociais, desenvolvimento de novos comportamentos em relação ao autocontrole, maior aceitação de regras e limites, além de ganhos na autonomia e autoconfiança do praticante que refletem positivamente no cenário escolar.

O nível de atenção e foco nas atividades realizadas pelo P4 apresentou grandes mudanças ao longo do ano, visto que, nos primeiros meses, ele estava sempre desconcentrado e alheio ao que estava sendo feito pelo grupo e, com o tempo, ele foi se engajando mais nas atividades e focando no que estava sendo feito, e os episódios de desatenção se dissiparam drasticamente. No que diz respeito às atividades pedagógicas, no fim do ano o praticante já estava conseguindo formar frases e palavras simples e, no desenvolvimento matemático, não foram observados progressos.

Quanto à concentração e atenção do $\mathrm{P} 5$, houve bom progresso considerando o desenvolvimento do vínculo com a equipe, uma vez que, nas primeiras sessões, o praticante a mantinha apenas para si, não atendendo ao contato com o outro nem interagindo com o ambiente ao seu redor, o que se ampliou com o tempo, e ele passou a voltar sua atenção para as atividades que eram realizadas, bem como para o ambiente ao seu redor, participando ativamente, como ao pedir que lhe déssemos folhas da árvore, brincando com estas e, até mesmo, contando histórias conforme o que via durante os percursos.

Com relação à atenção e concentração, a qual inicialmente delimitava somente para si mesmo, o P6 passou a demonstrar atenção para os movimentos e reações do cavalo, bem como para conversas e interações com a equipe, como já citado anteriormente, e também ao ambiente externo, passando a nomear as coisas à sua volta, caracterizá-las e mesmo procurá-las. Segundo Silva et al. (2012), a atenção concentrada é um dos maiores problemas para um aluno com TEA, e a Equoterapia vem estimular o desenvolvimento dessa e do raciocínio lógico, estimulando a criança a 
Utilizando a equoterapia como ferramenta psicopedagógica para crianças com necessidades educativas especiais

pensar antes de agir e melhorando num todo o seu convívio social, o que traz um nítido avanço, principalmente em seu aprendizado. Ward et al. (2013) observaram aumento na interação social, melhora no processamento sensorial e diminuição na gravidade dos sintomas associados ao espectro do autismo.

Considerando que, nas primeiras sessões, o P7 não interagiu verbalmente com a equipe e, no decorrer das sessões, desenvolveu habilidades sociais importantíssimas para o seu convívio no ambiente escolar e familiar, corroboramos com os resultados obtidos por Tan e Simmonds (2017), que afirmaram que a Equoterapia é percebida pelos pais como tendo vários níveis de benefícios psicossociais para seus filhos portadores do Transtorno do espectro autista. Segundo Silva et al. (2012), a atenção concentrada é um dos maiores problemas para um aluno com TEA, e a Equoterapia vem estimular o desenvolvimento desta e do raciocínio lógico, estimulando a criança a pensar antes de agir e melhorando num todo o seu convívio social, o que traz um nítido avanço, principalmente em seu aprendizado. Rodrigues e Costa (2013) evidenciaram que a Equoterapia pode ser uma alternativa eficaz no desenvolvimento da capacidade de manter a atenção e concentração, estabelecer vínculos afetivos e a autoconfiança dos indivíduos que a praticam.

Adicionalmente os resultados apresentados e discutidos no estudo de Prestes, Weiss e Araújo (2010) permitem afirmar que o desenvolvimento motor, bastante estimulado durante a prática da equoterapia, está estritamente relacionado à constituição de diferentes elementos que compõem a autoestima, e esses dois aspectos do desenvolvimento humano possuem relação intrínseca com fatores cognitivos necessários para o sucesso escolar.

Coelho (2007) observou que a equoterapia proporciona e facilita a aprendizagem da leitura, da escrita e do raciocínio matemático, além de promover a autoestima, autoimagem e autoconfiança, facilitando e acelerando os processos de aprendizagem.

Para Storer, Oliveira e Tupan (2003), a equoterapia pode apoiar a educação de crianças com déficits de aprendizado e alterações físicas e/ou mentais, com condutas sociais atípicas e com altas habilidades. Pode ser trabalhado pelo método o desenvolvimento da aprendizagem através das 
atividades educativas e psicomotoras, em que os ganhos reais da equoterapia são alcançados por participação ativa do praticante em todo processo, sob seus limites.

\section{CONSIDERAÇÕES FINAIS}

A Equoterapia vem sendo indicada por vários profissionais da área da saúde e educação como tratamento complementar de diferentes transtornos e patologias com objetivo de atingir benefícios físicos, psicológicos, emocionais e sociais. Nesse sentido, por meio do programa de intervenção com equoterapia, buscou-se proporcionar às crianças com dificuldade de aprendizagem oportunidades para que fortalecessem as diferentes áreas do desenvolvimento motor, cognitivo e social, com o intuito de melhorar seu desempenho escolar e também habilidades sociais importantíssimas para o seu convivo no ambiente escolar e familiar.

Durante a execução deste estudo, alguns aspectos merecem ser ressaltados com objetivo de orientar possíveis reproduções futuras deste estudo ou de estudos similares.

Com os recursos disponibilizados pelas entidades financiadoras, foi possível adquirir diversos testes para avaliar diferentes aspectos do público-alvo. O PROLEC, teste selecionado para esta atividade, é uma ferramenta eficaz capaz de identificar as dificuldades que interferem no processo de desenvolvimento da leitura, atuando como um guia para orientar programas de recuperação. É um teste muito utilizado por vários profissionais como fonoaudiólogos/terapeutas da fala, psicólogos e pedagogos, para a avaliação de crianças com dislexia e/ou com dificuldades de aprendizagem. proporcionando uma informação completa, resultando no diagnóstico dos transtornos da aprendizagem, sendo considerado o teste de referência no âmbito da leitura. No entanto, a julgar pelo fato de que apenas um indivíduo conseguiu realizar todas etapas do teste, caberá ao pesquisador recorrer a outra ferramenta mais adaptada a indivíduos portadores de TEA para concluir seu diagnóstico. Salientamos a importância de realizar o teste no início e no final do estudo para posterior comparação do resultado.

Outro fato que merece destaque é a importância de associar às Sessões de Equoterapia, atividades lúdicas complementares, principalmente 
quando o objetivo do estudo é promover ganhos no aprendizado. Todas as atividades desenvolvidas neste estudo de forma complementar às sessões foram realizadas com jogos pedagógicos adquiridos em estabelecimentos especializados na venda desse tipo de material de apoio.

A participação dos pais e professores é fundamental durante todo o desenvolvimento do estudo, uma vez que as informações que eles fornecem irá subsidiar a elaboração de relatórios que darão suporte aos resultados.

Finalmente, em se tratando de Equoterapia, é necessário observar que os benefícios devem ser registrados como um todo, uma vez que afetam de forma global o desenvolvimento do praticante, interferindo direta ou indiretamente nos objetivos que desejamos alcançar. Este estudo comprova que benefícios físicos, cognitivos e sociais interferem diretamente no desempenho do praticante em seu ambiente escolar, promovendo assim benefícios na esfera educacional de crianças com necessidades educativas especiais.

\section{Agradecimentos}

O desenvolvimento deste estudo foi possível graças ao financiamento e apoio da Fundação de Amparo à Pesquisa do Estado de Mato Grosso (FAPEMAT) por meio do Edital Universal 005/2015, do Ministério da Educação, através do financiamento obtido pelo Edital PROEXT 2016, da Universidade Federal de Mato Grosso pelo edital PBEXT 2016, da Universidade de Cuiabá e das parcerias com o Rancho Dourado e Rancho Raça Forte, bem como o empenho e dedicação de toda equipe deste projeto de equoterapia, e a participação imprescindível dos familiares e das professoras que assistiram essas crianças no decorrer do ano letivo, e que foram de fundamental importância no desenvolvimento deste trabalho.

\section{REFERÊNCIAS}

ANDERSON, S.; MEINTS, K. Brief report: the effects of equine-assisted activities on the social functioning in children and adolescents with autism spectrum. Journal of Autism and Developmental Disorders, v. 46, n. 10, p. 3344-52, oct. 2016.

BASS, M. M.; DUCHOWNY C. A.; LLABRE, M. M. The effect of therapeutic horseback riding on social functioning in children with autism. Journal of Autism and Developmental Disorders, v. 39, n. 9, p. 1261-7, set. 2009. 
BENDER, D. D.; GUARANY, N. R. Efeito da equoterapia no desempenho funcional de crianças e adolescentes com autismo. Revista de Terapia Ocupacional da Universidade de São Paulo, v. 27, n. 3, p. 271-7, set./dez. 2017.

BORIONI, N.; MARINARO, P.; CELESTINI, S.; DEL SOLE, F.; MAGRO, R.; ZOPPI, D.; MATTEI, F.; DALL'ARMI, V.; MAZZARELLA, F.; CESARIO, A.; BONASSI, S. Effect of equestrian therapy and onotherapy in physical and psycho-social performances of adults with intellectual disability: a preliminary study of evaluation tools based on the ICF classification. Disability and Rehabilitation, v. 34, n. 4, p. 279-87, out. 2012.

CERINO, S.; BORGI, M.; FIORENTINI, I.; CORREALE, C.; LORI, A.; CIRULLI, F. Equineassisted intervention in a child diagnosed with autism spectrum disorder: a case report. Rivista di Psichiatria, v. 51, n. 6, p. 270-4, nov./dez. 2016.

CHAMPAGNE, D.; CORRIVEAU, H.; DUGAS, C. Effect of hippotherapy on motor proficiency and function in children with cerebral palsy who walk. Physical and Occupational Therapy in Pediatrics, v. 37, n. 1, p. 51-63, fev. 2017.

COELHO, L. C. A Equoterapia como um instrumento de reeducação psicomotora. 2007. 40p. Monografia (Especialização em Psicomotricidade) - Universidade Cândido Mendes, Rio de Janeiro, 2007.

CUYPERS, K.; DE RIDDER, K.; STRANDHEIM, A. The effect of therapeutic horseback riding on 5 children with attention deficit hyperactivity disorder: a pilot study. Journal of Alternative and Complementary Medicine, v. 17, n. 10, p. 901-8, out. 2011.

DENZIN, N. K.; LINCOLN, Y. S. Handbook of qualitative research. London: Sage Publication, 1994.

FERREIRA, C. A. M.; THOMPSON, R. (Org.). Imagem e esquema corporal. São Paulo: Lovise, 2002.

GABRIELS, R. L.; PAN, Z.; DECHANT, B.; AGNEW, J. A.; BRIM, N.; MESIBOV, G. Randomized controlled trial of therapeutic horseback riding in children and adolescents with autism spectrum disorder. Journal of the American Academy of Child \& Adolescent Psychiatry, v. 54, n. 7, p. 541-9, jul. 2015.

HARRIS, A.; WILLIAMS, J. M. The impact of a horse riding intervention on the social functioning of children with autism spectrum disorder. International Journal of Environmental Research an Public Health, v. 14, n. 7, jul. 2017.

HOLM, M. B.; BAIRD, J. M.; KIM, Y. J.; RAJORA, K. B.; D'SILVA, D.; PODOLINSKY, L.; MAZEFSKY, C.; MINSHEW, N. Therapeutic horseback riding outcomes of parentidentified goals for children with autism spectrum disorder: an ABA' multiple case design examining dosing and generalization to the home and community. Journal of Autism and Developmental Disorders, v. 44, n. 4, p. 937-47, abr. 2014. 
Utilizando a equoterapia como ferramenta psicopedagógica para crianças com necessidades educativas especiais

JANG, C. H.; JOO, M. C.; NOH, S. E.; LEE, S. Y.; LEE, D. B.; LEE, S. H.; KIM, H. K.; PARK, $\mathrm{H}$. I. Effects of hippotherapy on psychosocial aspects in children with cerebral palsy and their caregivers: a pilot study. Annals of Rehabilitation Medicine, v. 40, n. 2, p. 230-6, abr. 2016.

LAKATOS, E. M.; MARCONI, M. de A. Fundamentos de metodologia científica. 4. ed. São Paulo: Atlas, 2001. 288p.

LANNING, B. A.; BAIER, M. E.; IVEY-HATZ, J.; KRENEK, N.; TUBBS, J. D. Effects of equine assisted activities on autism spectrum disorder. Journal of Autism and Developmental Disorders, v. 44, n. 8, p. 1897-907, ago. 2014.

LLAMBIAS, C.; MAGILL-EVANS, J.; SMITH, V.; WARREN, S. Equine-assisted occupational therapy: increasing engagement for children with autism spectrum disorder. The American Journal of Occupational Therapy, v. 70, n. 6, p. 1-9, nov./ dez. 2016.

MINAYO, M. C. S. (Org.). Pesquisa social: teoria, método e criatividade. Petrópolis, RJ: Vozes, 2002.

MORAES, A. G.; COPETTI, F.; ANGELO, V. R.; CHIAVOLONI, L. L.; DAVID, A. C. The effects of hippotherapy on postural balance and functional ability in children with cerebral palsy. Journal of Physical Therapy Science, v. 28, n. 8, p. 2220-6, ago. 2016.

O'HAIRE, M. E. Animal-assisted intervention for autism spectrum disorder: a systematic literature review. Journal of Autism and Developmental Disorders, v. 43, n. 7, p. 1606-22, jul. 2013.

PETTY, J. D.; PAN, Z.; DECHANT, B.; GABRIELS, R. L. Therapeutic horseback riding crossover effects of attachment behaviors with family pets in a sample of children with autism spectrum disorder. International Journal of Environmental Research and Public Health, v. 14, n. 3, mar. 2017.

PRESTES, D. B.; WEISSB, S.; ARAÚJO, J. C. O. A equoterapia no desenvolvimento motor e autopercepção de escolares com dificuldade de aprendizagem. Ciências e Cognição, Rio de Janeiro, v. 15, n. 3, p. 192-203, dez. 2010.

RODRIGUES, P. O.; COSTA, J. B. O. Equoterapia e aprendizagem da criança com transtorno de déficit de atenção e hiperatividade: um estudo de caso. In: ENCONTRO DE ENSINO, PESQUISA E EXTENSÃO, Presidente Prudente, 21 a 24 de outubro, 2013. Disponível em: <http://docplayer.com.br/14098522-Equoterapia-e-aprendizagemda-crianca-com-transtorno-de-deficit-de-atencao-e-hiperetividade-um-estudode-caso.html>.

SILVA, A. S.; BECKER, M. D.; MARTEL, S.; PERANZONI, V. C. Benefícios da equoterapia para alunos com déficit de atenção e hiperatividade. In: SEMINÁRIO 
INTERINSTITUCIONAL DE ENSINO, PESQUISA E EXTENSÃO DA UNICRUZ, 17. Anais... Cruz Alta, RS: UNICRUZ, nov. 2012.

SOUZA, M. B.; SILVA, P. L. N. Equoterapia no tratamento do transtorno do espectro autista. Revista Ciência e Conhecimento, São Jerônimo, RS, v. 9, n. 1, 2015.

STERGIOU, A.; TZOUFI, M.; NTZANI, E.; VARVAROUSIS, D.; BERIS A.; PLOUMIS, A. Therapeutic effects of horseback riding interventions: a systematic review and meta-analysis. American Journal of Physical Medicine \& Rehabilitation, v. 96, n. 10, p. 717-25, out. 2017.

STORER, M. R. S.; OLIVEIRA, M. R. V.; TUPAN, M. C. Contribuições da equoterapia na atuação psicopedagógica. In: ENCONTRO PARANAENSE DE PSICOPEDAGOGIA - ABPppr, 1. Maringá, nov. 2003. Disponível em: <http://www.sld.cu/galerias/pdf/ sitios/rehabilitacion-equino/contribuicoes_da_equoterapia_na_atuacao.pdf $>$.

TAN, V. X.; SIMMONDS, J. G. Parent perceptions of psychosocial outcomes of equine-assisted interventions for children with autism spectrum disorder. Journal of Autism and Developmental Disorders, v. 48, n. 3, p. 759-69, dez. 2017.

WARD, S. C.; WHALON, K.; RUSNAK, K.; WENDELL, K.; PASCHALL, N. The association between therapeutic horseback riding and the social communication and sensory reactions of children with autism. Journal of Autism and Developmental Disorders, v. 43, n. 9, p. 2190-8, set. 2013. 